\title{
$\$$ Research Square

\section{Hypophosphataemia after ferric carboxymaltose is unrelated to symptoms, intestinal inflammation or vitamin D status}

\section{Wendy Fang}

Eastern Health

\section{Rachel Kenny}

Monash University Eastern Health Clinical School

\section{Qurat-ul-Ain Rizvi}

Eastern Health

\section{Lawrence P. McMahon}

Monash University Eastern Health Clinical School

Mayur Garg ( $\nabla$ mayur.garg@monash.edu )

Royal Melbourne Hospital https://orcid.org/0000-0002-9149-3589

\section{Research article}

Keywords: Iron deficiency, ferric carboxymaltose, inflammatory bowel disease, hypophosphataemia, vitamin D

Posted Date: May 15th, 2020

DOI: https://doi.org/10.21203/rs.2.21308/v4

License: (1) This work is licensed under a Creative Commons Attribution 4.0 International License. Read Full License

Version of Record: A version of this preprint was published at BMC Gastroenterology on June 10th, 2020. See the published version at https://doi.org/10.1186/s12876-020-01298-9. 


\section{Abstract}

Background Intravenous iron replacement is recommended for iron-deficient patients with inflammatory bowel disease (IBD), but may be associated with hypophosphataemia, predisposing to osteomalacia and fractures. This study aimed to evaluate the incidence and risk factors for hypophosphataemia following intravenous ferric carboxymaltose (FCM) in patients with IBD.

Methods This prospective observational study of patients with and without IBD evaluated serum phosphate for 28 days following intravenous FCM, and assessed associations with symptoms, markers of inflammation and vitamin D status.

Results 24 patients with IBD (11 with Crohn's disease [CD], 13 with ulcerative colitis [UC], mean age 45 years [range 19-90], 7 female), and 20 patients without IBD (mean age 56 [22-88]y, 11 female), were included. Overall, serum phosphate declined by a mean of $36 \%$ at Day 7 , with a mean fall of $42 \%$ (SD $19 \%)$ at some time point over 28 days $(p<0.001)$. Twenty-four of $44(55 \%)$ patients developed moderate to severe hypophosphataemia (serum phosphate $<0.6 \mathrm{mmol} / \mathrm{L}$ ). No differences between patients with and without IBD were seen, but patients with $C D$ had greater decline in phosphate than those with UC. There was no association between hypophosphataemia and symptomatic adverse events, faecal calprotectin, C-reactive protein, albumin, platelet count, $25(\mathrm{OH})$ vitamin $\mathrm{D}$, or 1,25(di-OH) vitamin D. Serum phosphate $<1.05 \mathrm{mmol} / \mathrm{L}$ on Day 2 predicted susceptibility to moderate-severe hypophosphataemia (OR 7.0).

Conclusions Hypophosphataemia following FCM is common, unrelated to symptomatic adverse events, baseline intestinal or systemic inflammation, or vitamin $\mathrm{D}$ status.

\section{Background}

Iron deficiency, with or without anaemia, is one of the commonest systemic complications in patients with inflammatory bowel disease (IBD), affecting between 13 and $90 \%$ of patients.[1-4] Iron deficiency anaemia in patients with IBD is considered a marker of disease activity, and is associated with a reduced quality of life, impaired cognition and social functioning, and an increased risk of hospitalisation.[5-7] Recognition and correction of iron deficiency independent of IBD activity is associated with an improvement in these parameters, $[7,8]$ and intravenous iron is recommended for patients with moderate to severe anaemia or intolerance to oral iron formulations. $[2,4,5,9]$

Modern intravenous iron formulations are considered safe in patients with IBD, with treatment-related adverse events described in 10-30\% of patients, including nasopharyngitis, headaches, back pain, nausea or flu-like symptoms.[10-14]

Hypophosphataemia following intravenous iron, especially following ferric carboxymaltose (FCM), is increasingly recognised, likely mediated by a transient increase in intact fibroblast growth factor-23 (iFGF- 
23) due to inhibition of its cleavage, which results in phosphaturia.[15-17] When recurrent or persistent, this may result in osteomalacia and fractures.[16, 18]

Of particular relevance to patients with IBD, repeated iron infusions, malnutrition and vitamin D deficiency may aggravate risk of hypophosphataemia.[19] Furthermore, iFGF-23 is upregulated by systemic inflammation, which may, theoretically, be a further risk factor for hypophosphataemia in patients with IBD.[20] This study aimed to prospectively evaluate the incidence and severity of intravenous FCMassociated hypophosphataemia in patients with and without IBD, its association with symptoms, and ascertain associated risk factors including systemic and intestinal inflammation, and vitamin D status, to enable potential preventative strategies.

\section{Methods}

\section{Subjects}

Consecutive non-pregnant iron-deficient patients with and without IBD attending a tertiary gastroenterology unit, who were deemed to require intravenous FCM as per clinician judgement, were invited to participate. Patients had evidence of iron deficiency based upon ferritin $<30 \mathrm{ng} / \mathrm{ml}$ or ferritin $<$ $100 \mathrm{ng} / \mathrm{ml}$ with evidence of blood loss or inflammation. Non-IBD controls had iron deficiency secondary to occult or overt gastrointestinal bleeding $(n=16)$ or menstrual blood loss $(n=4)$.

\section{Protocol and analytical assays}

One gram FCM was administered to all patients. Baseline demographics and disease characteristics, haematological and biochemical indices, 25-hydroxy vitamin D and serum for analysis of iFGF-23, Cterminal FGF-23 (cFGF-23, the cleaved fragment of iFGF-23) and vitamin D binding protein (DBP), were collected. Faecal samples were analysed for calprotectin by fluorescence enzyme immunoassay (Phadia 100 Eli $^{\mathrm{TM}}{ }^{\mathrm{M}}$ Calprotectin, Thermo Scientific, Scoresby, Australia). Clinical and biochemical assessment was repeated $2,4,7,14$ and 28 days after infusion, including direct questioning of gastrointestinal symptoms and adverse events, and serum stored for analysis of iFGF-23 and cFGF-23 at Days 2, 7 and 28.

Serum iFGF-23 was analysed in duplicate by enzyme-linked immunosorbent assay (ELISA, Kainos, Shizuoka, Japan), as previously described.[21] Serum cFGF-23 was analysed in duplicate by ELISA (Immunotopics, San Clemente, CA, USA), as described previously.[21]

\section{Endpoints}

The endpoints for this study included mean reduction in serum phosphate levels from Day 0 to Day 7 , the proportion of patients experiencing a moderate (Grade 3, serum phosphate $<0.6 \mathrm{mmol} / \mathrm{L}$ ) to severe (Grade 4 toxicity, $<0.3 \mathrm{~mol} / \mathrm{L}$ ) hypophosphataemia according to Common Terminology Criteria for Adverse Events (CTCAE) [22] at any stage during the follow-up period, difference in rate of 
hypophosphataemia between patients with and without IBD, and correlation between hypophosphataemia and symptomatic adverse events, also graded according to CTCAE. The association of hypophosphataemia with degree of systemic (C-reactive protein) or intestinal (faecal calprotectin) inflammation, and serum vitamin D status was additionally evaluated.

\section{Statistical analyses}

Results were analysed by SPSS v23 (IBM Corp) and Graphpad Prism v6 (GraphPad Software, Inc, California, USA) using paired and unpaired t-tests, Fisher's exact test, and multiple regression analyses as appropriate. A two-tailed p-value of $<0.05$ was considered statistically significant for all associations.

\section{Ethical considerations}

The protocol for this study was approved by the Office of Research and Ethics at Eastern Health (LR 172017, approved 17 March 2017), and was performed in accordance with Australian regulations and the principles of the Declaration of Helsinki 1954 and its later amendments. Written, informed consent was obtained from all participants included in this study.

\section{Results}

Twenty-three non-IBD controls and 27 patients with IBD were recruited. Three patients from each group were excluded due to loss of follow-up within one week following infusion, leaving 24 patients with IBD (11 with Crohn's disease [CD] and 13 with ulcerative colitis [UC)]) and 20 non-IBD controls for analysis (Table 1). Characteristics of disease in patients with IBD are shown in Table 2.

Mean plasma haemoglobin improved similarly $(p=0.460)$ after 28 days in patients with $(121$ to $134 \mathrm{~g} / \mathrm{L})$ and without IBD (124 to $132 \mathrm{~g} / \mathrm{L})$.

\section{Change in serum phosphate}

Serum phosphate fell in 42 of 44 patients (95\%) following FCM. The overall mean fall in serum phosphate across all patients and time periods was $0.47 \mathrm{mmol} / \mathrm{L} \pm \mathrm{SD} 0.24(42 \pm 19 \%)$ compared with baseline. The lowest serum phosphate recorded was $0.26 \mathrm{mmol} / \mathrm{L}$ in a patient with UC at Day 7. Mean lowest serum phosphate levels were $36 \%$ lower at Day 7 , and remained lower at Day 28 compared to baseline (mean $0.95 \mathrm{vs} 1.10 \mathrm{mmol} / \mathrm{L}, \mathrm{p}=0.001$ ) (Figure 1a). Three patients had serum phosphate below $0.6 \mathrm{mmol} / \mathrm{L}$ at Day 28 (Table 3). The time to lowest serum phosphate was 2 days in 1 patient, 4 days in 8 patients, 7 days in 22 patients, 14 days in 10 patients, and 28 days in 3 patients.

Serum phosphate fell below $0.6 \mathrm{mmol} / \mathrm{L}$ in 24 of 44 patients (56\%), similar in patients with and without IBD (Table 4).

Patients with CD had a significantly greater maximal reduction in serum phosphate than patients with UC (mean reduction $51 \%$ vs $32 \%, p=0.029$ ) (Figure $1 b$ ). 


\section{Symptomatic adverse events}

Delayed adverse events were described by 11 patients with IBD (46\%) and 12 without IBD (60\%) (Supplementary Table 1). Fatigue, arthralgia, myalgia, headache, dyspnoea or dizziness were reported by 14 patients ( 6 with and 8 without IBD) in the first 7 days - these adverse events did not correlate with serum phosphate (Figure 1c).

\section{Change in FGF-23}

Baseline iFGF-23 and cFGF-23 levels were similar in patients with and without IBD. Across all patients, iFGF-23 increased by a mean of $84 \%(95 \% \mathrm{Cl} 26-139 \%$, $\mathrm{p}=0.004)$, peaking within 2 days, returning to baseline at Day 28. C-terminal FGF-23 levels remained stable at day 2, but gradually declined over time, with a significant reduction at Day 28 compared with baseline levels $(p=0.004$, paired t-test) (Figure 1d and e).

\section{Predictors of hypophosphataemia}

Across all participants, minimum serum phosphate correlated with baseline (Pearson $r=0.35, p=0.020$ ) and Day 2 (Pearson $r=0.65, p<0.001)$ phosphate levels (Figure 2a and $b$ ).

In patients with IBD, there was no correlation between minimum serum phosphate and markers of inflammation (faecal calprotectin, C-reactive protein, albumin, platelet count) or baseline 25-hydroxy vitamin D (Figure 2c-f).

A significant correlation between serum phosphate at Day 2 and minimum phosphate $(r=0.67, p<0.001)$ was noted (Supplementary Figure 1). Minimum serum phosphate did correlate with DBP $(r=0.48, p=$ $0.017)$ but showed a trend towards an inverse correlation with free 25-hydroxy vitamin $D(r=-0.39, p=$ $0.060)$ and less so with bioavailable $25(\mathrm{di}-\mathrm{OH}) \mathrm{D}(\mathrm{r}=-0.32, \mathrm{p}=0.124)$ (Supplementary Figure 1$)$.

On multiple regression analysis across all patients, baseline serum phosphate, Day 2 phosphate, Creactive protein, $25(\mathrm{OH})$ vitamin $\mathrm{D}, 1,25(\mathrm{di}-\mathrm{OH})$ vitamin $\mathrm{D}$, were evaluated as independent risk factors for minimum serum phosphate in the follow-up period. The strongest predictor was Day 2 phosphate ( $\beta$ $0.577, p<0.001)$, with baseline phosphate no longer significant $(\beta 0.165, p=0.259$, adjusted $R$ square 0.387). For patients with IBD only, a separate multiple regression model consisting of Day 2 phosphate, faecal calprotectin, DBP and free 25 -hydroxy vitamin D was developed. Only Day 2 phosphate ( $\beta 0.533, p$ $=0.052$ ) approached significance (adjusted R square 0.344).

When serum phosphate at Day 2 was $\geq 1.05 \mathrm{mmol} / \mathrm{L}$, the risk of Grade 3 or 4 hypophosphataemia during follow-up was $23 \%$ compared to a $67 \%$ risk (odds ratio $7.0,95 \% \mathrm{Cl} 1.6-32.0$ ) when Day 2 phosphate was $<1.05 \mathrm{mmol} / \mathrm{L}$.

\section{Discussion}


The risk of hypophosphataemia in patients receiving intravenous FCM is increasingly recognised; however, the risk in patients with IBD compared with patients without IBD, and associated predisposing factors, have not been previously reported. This prospective observational study demonstrated a mean phosphate reduction of $42 \%$ following FCM, similar in patients with and without IBD, with more than half the patients experiencing moderate to severe hypophosphataemia. Although patients with CD more frequently experienced hypophosphataemia than patients with UC, patients with IBD per se were not at greater risk than patients without. Importantly, neither the severity of inflammation (assessed by circulating or faecal markers) nor baseline vitamin D status predicted risk of hypophosphataemia.

Most cases of FCM-associated hypophosphataemia are asymptomatic. Indeed, our data show that delayed adverse events secondary to FCM have no relationship with hypophosphataemia, with the 6 patients with IBD and 8 patients without IBD who experienced fatigue, arthralgia, myalgia, headache and dyspnoea or dizziness have similar phosphate levels to those participants without these symptoms. Hence, hypophosphatemia is difficult to recognise unless specifically measured in the serum. In the largest randomised clinical trial of patients with IBD who received FCM, mean serum phosphate was noted to fall by $38 \%$ from baseline $(1.12 \pm 0.22 \mathrm{mmol} / \mathrm{L})$ to Week $2(0.69 \pm 0.24 \mathrm{mmol} / \mathrm{L})$.[13] Hypophosphataemia as an adverse event was reported in only 6 of 244 patients in that study, and none in a follow-up maintenance study of 104 patients,[12] presumably due to most cases being asymptomatic.

Though most cases of hypophosphataemia appear transient, a minority of patients have persistent reduction in serum phosphate for up to several months. In our current study, serum phosphate remained lower at Day 28 compared to baseline (mean $0.95 \mathrm{vs} 1.10 \mathrm{mmol} / \mathrm{L}, \mathrm{p}=0.001$ ), and in 3 patients remained below $0.6 \mathrm{mmol} / \mathrm{L}$. In another recent study, $56.9 \%$ of 52 patients receiving FCM were noted to have moderate to severe hypophosphataemia (defined in this study as $<0.65 \mathrm{mmol} / \mathrm{L}$ ) at 2 weeks, with $13.7 \%$ of patients continuing to have serum phosphate below this level at 6 weeks, and some for up to 6 months.[17] Retrospective studies have also reported hypophosphatemia for as long as 6 months following intravenous iron.[16, 23]

This persistent reduction in serum phosphate, particularly in the context of repeated iron infusions, may contribute to hypophosphatemic osteomalacia with fractures, $[18,24,25]$ which may have delayed clinical recognition due to the non-specific nature of symptoms reported by patients and often normal plain radiography. Given that patients with IBD may have nutritional deficiencies and reduced bone density, they may be particularly susceptible to these complications.[19] Furthermore, iFGF-23 is also known to be upregulated by systemic inflammation, potentially further predisposing to hypophosphataemia.[20] Nonetheless, baseline levels of iFGF-23 were similar in patients with and without IBD in the current study. Though not performed in this study, measurement of bone turnover markers following FCM in a future study may help to stratify risk of osteomalacia in the long-term.

Eliciting risk factors for hypophosphataemia following FCM, especially in patients with IBD is, therefore, crucial, to develop potential preventative strategies. The absence of any association between systemic or 
intestinal inflammation, or vitamin D components (25-hydroxy vitamin D, 1,25(di-OH)D, free or bioavailable 25-hydroxy vitamin $\mathrm{D}$ ), with risk of hypophosphataemia, means that correction of these factors may not be the answer.

Interestingly, a significant correlation between DBP and the lowest serum phosphate was noted. DBP is a liver-derived a-globulin structurally similar to albumin, which binds about $85-90 \%$ of circulating vitamin D metabolites.[26] DBP may control the availability of vitamin D metabolites, especially 25 -hydroxy vitamin $D$, to tissues by allowing only the small free fraction to passively enter cells through diffusion across cell membranes, or actively via interaction with membrane glycoproteins megalin and cubulin.[27] Higher concentrations of DBP may directly reduce circulating 1,25 dihydroxy vitamin D.[28] In contrast, FGF-23 inhibits cytochrome P27B1, the enzyme which 1-hydroxylates 25-hydroxy vitamin D to 1,25 dihydroxy vitamin D. The potential relationship between DBP, FGF-23, 1,25 dihydroxy vitamin D and serum phosphate warrants further study.

The mechanism of hypophosphataemia following intravenous iron administration, specifically after FCM, has been investigated in numerous studies. $[15,29,30]$ Consistent with previous reports, the hormone iFGF-23, which primarily inhibits renal phosphate reabsorption producing phosphate wasting but also reduces circulating $1,25(\mathrm{di}-\mathrm{OH}) \mathrm{D}$ and thus intestinal phosphate absorption,[15, 29,30] was demonstrated to have significantly risen by Day 2 in our study. Changes in C-terminal FGF-23 should generally be interpreted with some caution as the assay detects both cFGF-23 fragments and the intact molecule. Given that levels remained relatively stable, it is likely that impaired intracellular degradation of iFGF-23 is the likely explanation for the observed changes in FGF-23.[15] The timing of peak of iFGF-23 is uncertain, with initial studies describing a peak at day 1,[15] and other studies reporting a peak at Day 2.[29, 30] Both days 1 and 2 have not been published in a single study, and hence the precise trajectory of iFGF-23 in the first 2-3 days remains uncertain. The decline by day 7 has been consistently reported previously. $[15,29,30]$

Though patients with and without IBD did not differ in rates of hypophosphataemia, patients with CD had a higher risk of hypophosphataemia than those with UC. Subgroup analysis based upon the location of $C D$ was not possible, since only 2 of 11 patients with $C D$ had isolated colonic disease, with most having ileal or ileocolonic disease. Given that phosphate is absorbed in the small intestine, the difference between patients with $C D$ and UC might be accounted for by a greater susceptibility to malabsorption of phosphate in patients with $C D$ and requires further investigation. It is worth noting, however, that baseline phosphate was similar in patients with CD and UC $(p=0.34)$.

FCM is one of the most commonly prescribed formulations of intravenous iron worldwide, but emerging studies demonstrate a significantly higher risk of hypophosphataemia following FCM compared to other intravenous iron formulations such as iron dextran, iron isomaltoside, and ferumoxytol.[15, 17, 31] The reasons for this difference are unclear, but may be secondary to a differential effect on cleavage of iFGF23 in osteocytes by differing carbohydrate moieties.[15] Although apparently consistent, such serological effects need to be balanced against the relative clinical safety and the limited sequelae of 
FCM noted to date, particularly in comparison to other formulations such as iron dextran. Longer studies with more rigorous endpoints will enable a clearer distinction to be made.

The strength of this study lies in the uniform, prospective collection of data in patients with and without IBD, and its ability to clarify rates of hypophosphataemia as well as pertinent risk factors. Nonetheless, it must be acknowledged that fractional urinary phosphate excretion was not measured in patients.

Previous studies have shown that an increase in phosphaturia is the primary mechanism for hypophosphataemia following intravenous iron, but whether this effect differs between patients with and without IBD, or is influenced by systemic inflammation, is an area for further study. Secondly, the duration of persistence of hypophosphataemia beyond 4-6 weeks and effect on bone turnover markers in this population remains undetermined, particularly in relation to the presence or type of IBD, and remains an avenue for further investigation.

\section{Conclusions}

Hypophosphataemia following FCM occurs at similar rates in patients with and without IBD, and is not influenced by inflammation, or vitamin D status. Alternative intravenous iron formulations associated with a lower risk of hypophosphataemia might be considered for iron replacement in such patients.

\section{Abbreviations}

\begin{tabular}{ll} 
CD & Crohn's disease \\
\hline CTCAE & Common Terminology Criteria for Adverse Events \\
\hline DBP & Vitamin D binding protein \\
\hline ELISA & Enzyme-linked immunosorbent assay \\
\hline FCM & Ferric carboxymaltose \\
\hline FGF23 & Fibroblast growth factor-23 \\
\hline CFGF & C-terminal fibroblast growth factor-23 \\
\hline iFGF & Intact fibroblast growth factor-23 \\
\hline IBD & Inflammatory bowel disease \\
\hline UC & Ulcerative colitis
\end{tabular}

\section{Declarations}

\section{Ethics approval and consent to participate}

The protocol for this study was approved by the Office of Research and Ethics at Eastern Health, Victoria, Australia (LR17-2017), and performed in accordance with the Declaration of Helsinki and its later 
modifications. Written informed consent was obtained from all participants in this study.

\section{Consent to publish}

All authors agree with the content of the manuscript and consent for its final submission. All participants gave written consent for their de-identified personal or clinical details to be published in this study.

\section{Availability of data and materials}

The authors declare that the data generated or analysed in this study are available within the paper and its supplementary materials.

\section{Competing interests}

LM has served on the advisory boards and received speaker fees, research or travel grants from Pfizer, Pharmacosmos, Amgen, Roche and Vifor Pharma.

MG has served on the advisory board of Pfizer and Pharmacosmos and has received speaker fees, research or travel grants from Abbvie, Janssen, Pfizer, Pharmacosmos, Shire, Takeda and Vifor.

All other authors have no disclosures.

\section{Funding}

This work was supported by a research grant from Pharmacosmos, Denmark. Pharmacosmos had no input regarding the research or research protocol for this investigator-initiated study.

\section{Author contributions}

Each author's contribution is as follows:

- WF: acquisition of data, analysis and interpretation of data, writing and drafting the article and its final approval;

- RK: acquisition of data, critical appraisal of manuscript for important intellectual content, final approval of submitted version;

- QR: acquisition of data, critical appraisal of manuscript for important intellectual content, final approval of submitted version;

- LM: design of study, critical appraisal of manuscript for important intellectual content, final approval of submitted version;

- MG: conception and design of the study, analysis and interpretation of data, writing and drafting the article, final approval.

All authors have read and approved the manuscript. 
Nil.

\section{References}

1. Cappellini MD, Comin-Colet J, de Francisco A, Dignass A, Doehner W, Lam CS, Macdougall IC, Rogler G, Camaschella C, Kadir R: Iron deficiency across chronic inflammatory conditions: International expert opinion on definition, diagnosis, and management. American journal of hematology 2017, 92(10):1068-1078.

2. Kulnigg $S$, Gasche C: Systematic review: managing anaemia in Crohn's disease. Alimentary pharmacology \& therapeutics 2006, 24(11-12):1507-1523.

3. Wilson A, Reyes E, Ofman J: Prevalence and outcomes of anemia in inflammatory bowel disease: a systematic review of the literature. The American journal of medicine 2004, 116(7):44-49.

4. Mücke V, Mücke MM, Raine T, Bettenworth D: Diagnosis and treatment of anemia in patients with inflammatory bowel disease. Annals of gastroenterology: quarterly publication of the Hellenic Society of Gastroenterology 2017, 30(1):15.

5. Dignass AU, Gasche C, Bettenworth D, Birgegård G, Danese S, Gisbert JP, Gomollon F, lqbal T, Katsanos $\mathrm{K}$, Koutroubakis I: European consensus on the diagnosis and management of iron deficiency and anaemia in inflammatory bowel diseases. Journal of Crohn's and Colitis 2015, 9(3):211-222.

6. Ershler WB, Chen K, Reyes EB, Dubois R: Economic burden of patients with anemia in selected diseases. Value in Health 2005, 8(6):629-638.

7. Peyrin-Biroulet L, Lopez A, Cummings JF, Dignass A, Detlie TE, Danese S: treating-to-target for inflammatory bowel disease-associated anaemia. Alimentary pharmacology \& therapeutics 2018, 48(6):610-617.

8. Wells CW, Lewis S, Barton JR, Corbett S: Effects of changes in hemoglobin level on quality of life and cognitive function in inflammatory bowel disease patients. Inflammatory bowel diseases 2006, 12(2):123-130.

9. Gasche C, Berstad A, Befrits R, Beglinger C, Dignass A, Erichsen K, Gomollon F, Hjortswang H, Koutroubakis I, Kulnigg S: Guidelines on the diagnosis and management of iron deficiency and anemia in inflammatory bowel diseases. Inflammatory bowel diseases 2007, 13(12):1545-1553.

10. Garg M, Morrison G, Friedman A, Lau A, Lau D, Gibson P: A rapid infusion protocol is safe for total dose iron polymaltose: time for change. Internal medicine journal 2011, 41(7):548-554.

11. Kulnigg S, Stoinov S, Simanenkov V, Dudar LV, Karnafel W, Garcia LC, Sambuelli AM, D'haens G, Gasche C: A novel intravenous iron formulation for treatment of anemia in inflammatory bowel disease: the ferric carboxymaltose (FERINJECT®) randomized controlled trial. The American journal of gastroenterology 2008, 103(5):1182-1192. 
12. Evstatiev R, Alexeeva O, Bokemeyer B, Chopey I, Felder M, Gudehus M, Iqbal T, Khalif I, Marteau P, Stein $\mathrm{J}$ : Ferric carboxymaltose prevents recurrence of anemia in patients with inflammatory bowel disease. Clinical Gastroenterology and Hepatology 2013, 11(3):269-277.

13. Evstatiev R, Marteau P, Iqbal T, Khalif IL, Stein J, Bokemeyer B, Chopey IV, Gutzwiller FS, Riopel L, Gasche C: FERGIcor, a randomized controlled trial on ferric carboxymaltose for iron deficiency anemia in inflammatory bowel disease. Gastroenterology 2011, 141(3):846-853. e842.

14. Dahlerup JF, Jacobsen BA, van der Woude J, Bark L-Å, Thomsen LL, Lindgren S: High-dose fast infusion of parenteral iron isomaltoside is efficacious in inflammatory bowel disease patients with iron-deficiency anaemia without profound changes in phosphate or fibroblast growth factor 23. Scandinavian journal of gastroenterology 2016, 51(11):1332-1338.

15. Wolf $M$, Koch TA, Bregman DB: Effects of iron deficiency anemia and its treatment on fibroblast growth factor 23 and phosphate homeostasis in women. J Bone Miner Res 2013, 28(8):1793-1803.

16. Schaefer B, Wurtinger P, Finkenstedt A, Braithwaite V, Viveiros A, Effenberger M, Sulzbacher I, Moschen A, Griesmacher A, Tilg $\mathrm{H}$ et al: Choice of High-Dose Intravenous Iron Preparation Determines Hypophosphatemia Risk. PloS one 2016, 11(12):e0167146.

17. Detlie TE, Lindstrom JC, Jahnsen ME, Finnes E, Zoller H, Moum B, Jahnsen J: Incidence of hypophosphatemia in patients with inflammatory bowel disease treated with ferric carboxymaltose or iron isomaltoside. Aliment Pharmacol Ther 2019, 50(4):397-406.

18. Fang W ML, Bloom S, Garg M: Symptomatic severe hypophosphatemia after intravenous ferric carboxymaltose. JGH Open 2019.

19. Garg M, Lubel J, Sparrow M, Holt S, Gibson P: Review article: vitamin D and inflammatory bowel disease-established concepts and future directions. Alimentary pharmacology \& therapeutics 2012, 36(4):324-344.

20. David V, Francis C, Babitt JL: Ironing out the crosstalk between FGF23 and inflammation. American Journal of Physiology-Renal Physiology 2017, 312(1):F1-F8.

21. Smith ER, McMahon LP, Holt SG: Method-specific differences in plasma fibroblast growth factor 23 measurement using four commercial ELISAs. Clinical chemistry and laboratory medicine 2013, 51(10):1971-1981.

22. Health UDo, Services H: Common Terminology Criteria for Adverse Events (CTCAE). Version 4.0 Published: May 28, 2009 (v4. 03: June 14, 2010). In.; 2016.

23. Hardy S, Vandemergel X: Intravenous iron administration and hypophosphatemia in clinical practice. Int J Rheumato/ 2015, 2015:468675.

24. Schaefer B, Glodny B, Zoller H: Blood and Bone Loser. Gastroenterology 2017, 152(6):e5-e6.

25. Zoller H, Schaefer B, Glodny B: Iron-induced hypophosphatemia: an emerging complication. Curr Opin Nephrol Hypertens 2017, 26(4):266-275.

26. Otterbein LR, Cosio C, Graceffa P, Dominguez R: Crystal structures of the vitamin D-binding protein and its complex with actin: structural basis of the actin-scavenger system. Proceedings of the National Academy of Sciences 2002, 99(12):8003-8008. 
27. Nykjaer A, Dragun D, Walther D, Vorum H, Jacobsen C, Herz J, Melsen F, Christensen El, Willnow TE: An endocytic pathway essential for renal uptake and activation of the steroid 25-(OH) vitamin D3. Cell 1999, 96(4):507-515.

28. Havens PL, Kiser JJ, Stephensen CB, Hazra R, Flynn PM, Wilson CM, Rutledge B, Bethel J, Pan CG, Woodhouse LR: Association of higher plasma vitamin $D$ binding protein and lower free calcitriol levels with tenofovir disoproxil fumarate use and plasma and intracellular tenofovir pharmacokinetics: cause of a functional vitamin D deficiency? Antimicrobial agents and chemotherapy 2013, 57(11):5619-5628.

29. Roberts MA, Huang L, Lee D, MacGinley R, Troster SM, Kent AB, Bansal SS, Macdougall IC, McMahon LP: Effects of intravenous iron on fibroblast growth factor 23 (FGF23) in haemodialysis patients: a randomized controlled trial. BMC Nephro/ 2016, 17(1):177.

30. Huang LL, Lee D, Troster SM, Kent AB, Roberts MA, Macdougall IC, McMahon LP: A controlled study of the effects of ferric carboxymaltose on bone and haematinic biomarkers in chronic kidney disease and pregnancy. Nephrology Dialysis Transplantation 2017.

31. Adkinson NF, Strauss WE, Macdougall IC, Bernard KE, Auerbach M, Kaper RF, Chertow GM, Krop JS: Comparative safety of intravenous ferumoxytol versus ferric carboxymaltose in iron deficiency anemia: A randomized trial. Am J Hematol 2018, 93(5):683-690.

\section{Tables}

Table 1. Baseline participant characteristics. 


\begin{tabular}{|c|c|c|c|}
\hline & $\begin{array}{c}\text { IBD } \\
(n=24)\end{array}$ & Non-IBD Controls $(n=20)$ & P value $^{\dagger}$ \\
\hline Age (mean $+/$ - range) & $45(19-90)$ & $56(22-88)$ & 0.045 \\
\hline Female:Male & $7: 17$ & $11: 9$ & $0.153^{\ddagger}$ \\
\hline \multicolumn{4}{|l|}{ Co-morbid illnesses, n (\%) } \\
\hline Type 2 diabetes mellitus & 2 & 3 & \\
\hline Chronic kidney disease & 1 & 0 & \\
\hline Atrial fibrillation & 1 & 0 & \\
\hline Ischaemic heart disease & 1 & 2 & \\
\hline Colorectal adenocarcinoma & 0 & 1 & \\
\hline Other cancer & 1 & 3 & \\
\hline Body mass index (mean $+/$ - range) & $26.9(17.6-51.3)$ & $26.5(5.43)$ & 0.866 \\
\hline Haemoglobin (g/L, mean, range) & $121(62-153)$ & $124(86-162)$ & 0.597 \\
\hline $\operatorname{MCV}\left(10^{-15} \mathrm{~L}\right.$, mean, range $)$ & $82(55-96)$ & $81(68-88)$ & 0.601 \\
\hline Serum ferritin ( $\mathrm{ng} / \mathrm{mL}$, mean, range) & $30(3-93)$ & $25(7-62)$ & 0.395 \\
\hline White cell count (X $10^{9} / \mathrm{L}$, mean, range) & $7.6(4.0-10.9)$ & $6.8(3.7-21.4)$ & 0.416 \\
\hline Platelet count ( $\times 10^{9} / \mathrm{L}$, mean, range) & $318(150-680)$ & $237(143-366)$ & 0.009 \\
\hline eGFR $\left(\mathrm{mL} / \mathrm{min} / 1.73 \mathrm{~m}^{2}\right.$, mean, range) & $85(38->90)$ & $80(45->90)$ & 0.273 \\
\hline Serum albumin ( $g / L$, mean, range) & $35(25-48)$ & $38(30-50)$ & 0.064 \\
\hline Serum C-reactive protein (mg/L, median, range) & $3(<2-18)$ & $<2(<2-15)$ & 0.228 \\
\hline Faecal calprotectin ( $\mu \mathrm{g} / \mathrm{g}$, median, range) & $573(<15->3000)$ & $47(<15-300)$ & 0.023 \\
\hline $25(\mathrm{OH})$ vitamin $\mathrm{D}(\mathrm{nmol} / \mathrm{L}$, mean, range) & $51(8-104)$ & $49(20-96)$ & 0.822 \\
\hline $1,25(\mathrm{di}-\mathrm{OH})$ vitamin $\mathrm{D}(\mathrm{pmol} / \mathrm{L}$, mean, range) & $112(50-202)$ & $136(62-263)$ & 0.109 \\
\hline Serum calcium (corrected, mmol/L, mean $\pm 95 \% \mathrm{CI}$ ) & $2.40(2.29-2.49)$ & $2.36(2.21-2.55)$ & 0.115 \\
\hline Serum phosphate $(\mathrm{mmol} / \mathrm{L}$, mean $\pm 95 \% \mathrm{CI})$ & $1.11(0.69-1.39)$ & $1.09(0.63-1.60)$ & 0.700 \\
\hline Serum parathyroid hormone (pmol/L, mean $\pm 95 \% \mathrm{CI})$ & $5.1(1.9-12.1)$ & $6.3(1.4-11.5)$ & 0.103 \\
\hline
\end{tabular}

${ }^{\dagger}$ Unpaired t-test unless otherwise specified.

${ }^{\ddagger}$ Chi-square 
Table 2. Characteristics of patients with IBD. 
Montreal Classification Number of

patients, $\mathrm{n}$

\begin{tabular}{cccc} 
Age at diagnosis $(\mathrm{y})$ & \multicolumn{3}{c}{ Disease extent } \\
\hline$<17$ & 2 & Proctitis & 0 \\
\hline $17-40$ & 6 & Left sided colitis & 7 \\
\hline$>40$ & 3 & Extensive colitis & 6 \\
\hline Location & & Disease severity & \\
\hline Ileal & 7 & Clinical remission & 0 \\
\hline Colonic & & Mild & 0
\end{tabular}

2

Ileocolonic

Moderate

2

\begin{tabular}{llll}
\hline Upper GI & 0 & Severe & 5 \\
\hline
\end{tabular}

\section{Behavior}

Non-stricturing, non- 4

penetrating

\begin{tabular}{ll}
\hline Stricturing & 5 \\
\hline
\end{tabular}

Penetrating / 2

fistulising

$\begin{array}{ll}\text { Perianal } & 1\end{array}$

Disease activity indices

Harvey Bradshaw Index $\quad 3 \quad$ Simple Clinical Colitis Activity $2(0-9)$

(median, range) $\quad(0-\quad$ Index (median, range)

8)

Medical therapy, Number of

\begin{tabular}{llc} 
Nil & 0 & 0 \\
\hline 5-ASAs only & 2 & 1 \\
\hline Steroids \pm 5-ASAs & 1 & 3 \\
\hline Azathioprine / 6-MP $\pm 5-$ & 1 & 3 \\
ASAs / steroids & &
\end{tabular}


steroids

IFX / ADA / vedolizumab 2

土 5-ASAs / steroids

IFX / ADA / vedolizumab

5

\pm immunomodulators

\section{Previous intestinal surgery /}

Jejunal resection

0

surgeries, Number of patients, n (\%)

Single ileo-colonic

3

0

resection

Multiple ileo-colonic

1

0

resections

Colectomy (total or

0

subtotal)

5ASAs, 5-aminosalicylates; 6-MP, 6-mercaptopurine; IFX, infliximab; ADA, adalimumab

Table 3. Number of patients with moderate to severe hypophosphataemia (serum PO4<0.6 mmol/L) according to visit day following ferric carboxymaltose (FCM)

\begin{tabular}{|l|c|c|}
\hline Visit day & IBD $(\mathrm{n}=24)$ & Non-IBD $(\mathrm{n}=20)$ \\
\hline Day 0 & 0 & 0 \\
\hline Day 2 & 1 & 2 \\
\hline Day 4 & 3 & 4 \\
\hline Day 7 & 9 & 5 \\
\hline Day 14 & 7 & 10 \\
\hline Day 28 & 1 & 2 \\
\hline
\end{tabular}

Table 4. Number of patients and degree of hypophosphataemia noted in first 28 days following ferric carboxymaltose (FCM) 


\begin{tabular}{|l|c|c|}
\hline Grade of hypophosphataemia $(\mathrm{mmol} / \mathrm{L})$ & IBD $(\mathrm{n}=24)$ & Non-IBD $(\mathrm{n}=20)$ \\
\hline Nil or Grade $1(\geq 0.80)$ & 7 & 5 \\
\hline Grade $2(0.60-<0.80)$ & 4 & 4 \\
\hline Grade $3(0.30-<0.60)$ & 12 & 11 \\
\hline Grade $4(<0.30)$ & 1 & 0 \\
\hline
\end{tabular}

Figures 


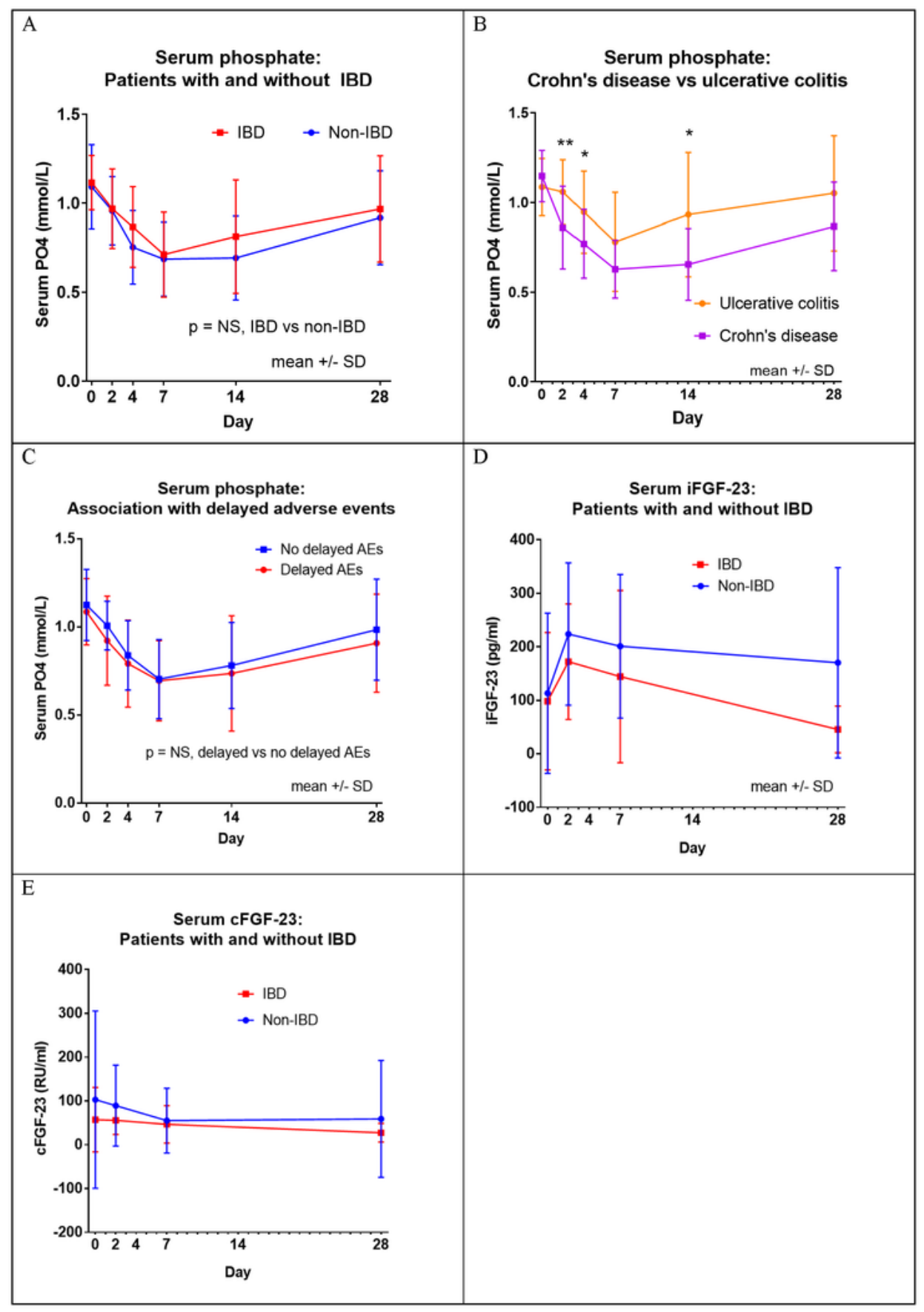

\section{Figure 1}

Change in (a) serum phosphate following ferric carboxymaltose infusion in patients with and without IBD; (b) change in serum phosphate in patients with Crohn's disease and ulcerative colitis; (c) association with symptomatic adverse events; (d) change in serum iFGF-23 and (e) cFGF-23 over the study period. 


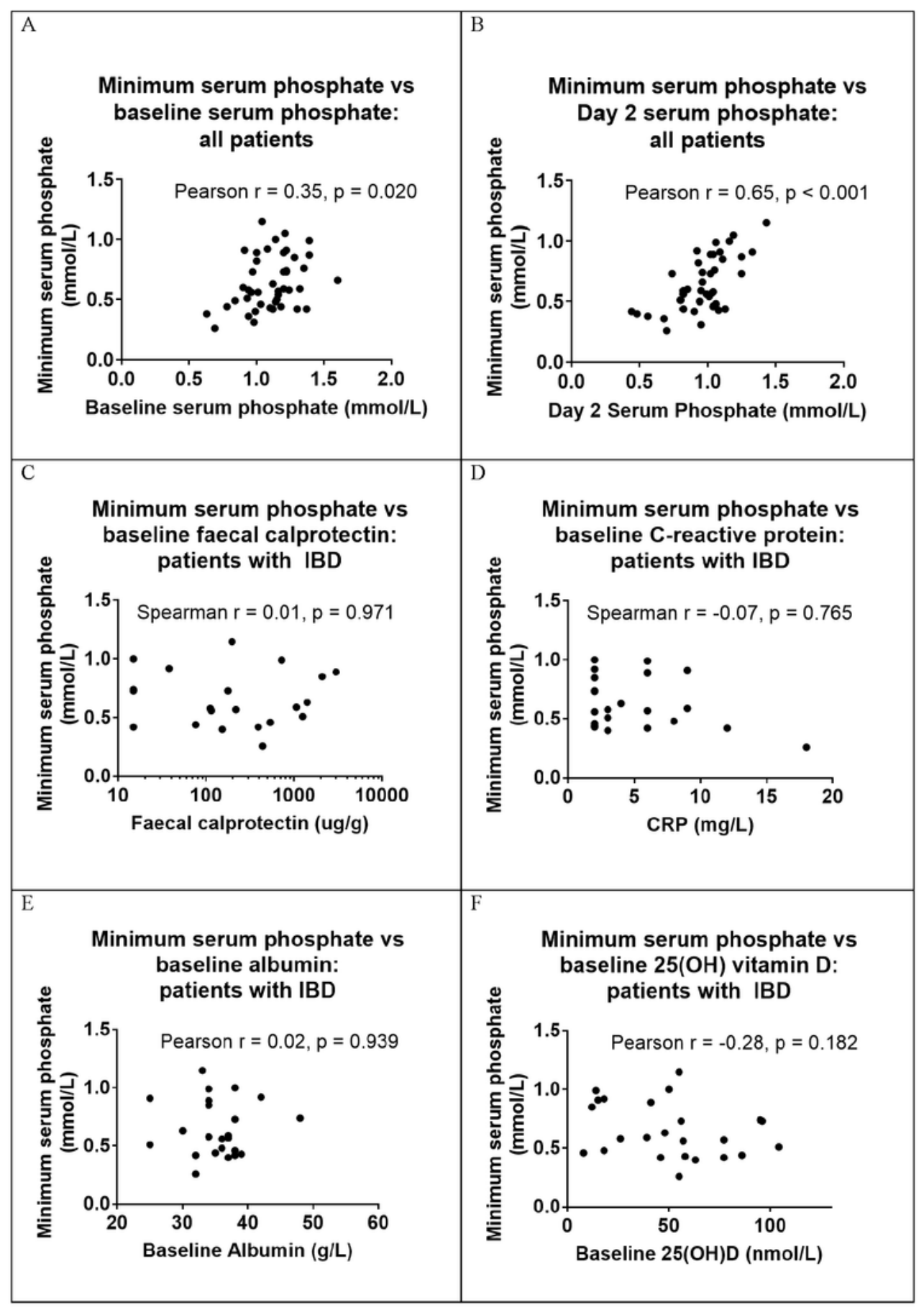

Figure 2

Correlation between minimum serum phosphate during follow-up and (a) baseline and (b) Day 2 serum phosphate, across all participants; (c) faecal calprotectin, (d) C-reactive protein, (e) albumin and (f) $25(\mathrm{OH})$ vitamin $\mathrm{D}$ in patients with IBD. 
This is a list of supplementary files associated with this preprint. Click to download.

- IRISIBDDatav5.xIsx

- SupplementaryMaterials.docx 